\title{
O sensacionismo de Fernando Pessoa em diálogo com a análise religiosa da arte de Paul Tillich
}

\author{
Joe Marçal Gonçalves dos Santos
}

Universidade Federal de Sergipe

\author{
Ivanilton Aragão de Moura \\ Universidade Federal de Sergipe
}

\section{Resumo}

O presente artigo desenvolve uma análise do Sensacionismo da estética modernista do poeta Fernando (António Nogueira) Pessoa (Portugal, 1888-1935) em diálogo com a teologia da arte de Paul Tillich (1886-1965). O objetivo do mesmo é definir a relação entre religião e literatura na modernidade como problema investigativo para uma abordagem do Sensacionismo como ideia central da poética pessoana e chave de compreensão de sua proposta teórica modernista. $\mathrm{Na}$ condição de projeto estético, o Sensacionismo representou a essência do modernismo português em sua primeira geração, tomando a sensação como categoria determinante para a poética, a compreensão e a expressão da condição humana. Desse modo, o Sensacionismo fornecia a Pessoa uma compreensão hermenêutica da arte intrinsecamente vinculada à vida. A problemática da investigação, por sua vez, investe na identificação e na análise do significado existencial-religioso do modernismo de Pessoa. Para tal, em um primeiro momento, situaremos a relação entre religião e arte na filosofia da cultura e da religião de Paul Tillich, destacando a compreensão hermenêutica de ambas a partir desse quadro conceitual. Em um segundo momento, definiremos o Sensacionismo como o conjunto dos pressupostos teóricos que nortearam a produção literária de Fernando Pessoa, a partir de seu Manifesto Sensacionista, bem como de um conjunto de poemas heteronímicos. Por fim, identificaremos, em torno da compreensão hermenêutica da arte, o potencial analítico da obra pessoana na perspectiva da teologia da arte de Paul Tillich. Palavras-chave: Religião; Literatura; Modernismo; Teoria estética; Poesia. 


\title{
Fernando Pessoa's sensationism in dialogue with the Paul Tillich's religious analysis of art
}

\begin{abstract}
This paper develops an analysis of the Sensationalism of the modernist aesthetics in the poetry of Fernando (António Nogueira) Pessoa (Portugal, 1888-1935) in dialogue with Paul Tillich's (1886-1965) theology of art. The goal is to define the relationship between religion and literature in the modernity as an investigative problem for an analysis of Sensationism as the central idea of Pessoa's poetics and the key to understanding his modernist theoretical proposal. As an aesthetics project, Sensationalism represents the essence of the first generation of Portuguese modernism, establishing sensation as the central category of poetry and the understanding of the human condition. As such, Sensationalism provided Pessoa of a hermeneutic comprehension of art that was intrinsically linked to life. The matter of investigation, in turn, is to identify and analyze the existential-religious meaning of Pessoa's modernism. To achieve that, we should first situate the relationship between art and religion in Tillich's philosophy of culture and religion. Our hermeneutic comprehension of art and religion will come from this conceptual framework. Secondly, we shall define Sensationalism as the set of theoretical assumptions that guided the literary production of Fernando Pessoa based on his Sensationalist Manifesto and some heteronymic poems. At last, we identify some aspects of the potential analysis of Pessoa's work in the perspective of Tillich's theology of art.
\end{abstract}

Keywords: Religion; Literature; Modernism; Aesthetic theory; Poetry.

\section{El sensacionismo de Fernando Pessoa en diálogo con el análisis religioso del arte de Paul Tillich}

\section{Resumen}

Este artículo analiza el Sensacionismo de la estética modernista del poeta Fernando (António Nogueira) Pessoa (Portugal, 1888-1935) en diálogo con la teología del arte de Paul Tillich (1886-1965). Su objetivo es definir la relación entre religión y literatura en el contexto de la modernidad como un problema de investigación para un acercamiento al Sensacionismo como idea central de la poética de Pessoa y su propuesta teórica modernista. Como proyecto estético, el Sensacionismo representó la esencia del modernismo portugués en su primera generación, tomando la sensación como categoría determinante para la poética, comprensión y expresión de la condición humana. De esta manera, el Sensacionismo proporcionó a Pessoa una comprensión hermenéutica del arte intrínsecamente vinculado a la vida. El problema de investigación, a su vez, hace uso de la identificación y análisis del significado existencial-religioso del modernismo de Pessoa. Para ello, en un primer momento, situaremos la relación entre religión y arte en la filosofía de la cultura y la religión de Paul Tillich, destacando la comprensión hermenéutica de ambas desde este marco conceptual. En un segundo paso, definiremos el Sensacionismo como el conjunto de supuestos teóricos que guiaron la producción literaria de Fernando Pessoa, a partir de su Manifiesto Sensacionista, así como un conjunto de poemas heteronímicos. Finalmente, identificaremos, en torno a 
la comprensión hermenéutica del arte, el potencial analítico de la obra pessoana en la perspectiva de la teología del arte de Paul Tillich.

Palabras-clave: Religión; Literatura; Modernismo; Teoría estética; Poesía.

\section{Introdução ${ }^{1}$}

A relação entre religião e literatura, como tema orientador do presente artigo, nos importa desde sua interface crítica à modernidade. Ambas sofrem da (e reagem à!) marginalização promovida pelos ditames da racionalidade moderna em torno do mesmo motivo: sua constituição simbólica e ficcional. A arte, contudo, nesse contexto, parece ter despontado como uma promessa mais convincente a uma cultura secularizada. Se a leitura de Eagleton (2016) está correta, isto se deu em função de um legado teológico romântico, mesmo que em sua negação - isto é, sob a efígie da nostalgia -, desde a qual, em contraste com a religião, a literatura e a arte permaneceram, mesmo nas condições críticas da modernidade, com um potencial redentivo de sentido baseado especialmente na expressividade poética, cuja efetivação se desvencilhou da experiência religiosa e se encaminhou nas veredas da estética.

É nesse quadro que o presente artigo aborda o Sensacionismo da estética modernista do poeta Fernando (António Nogueira) Pessoa (Portugal, 1888-1935) em diálogo com a teologia da arte de Paul Tillich (Alemanha/ EUA, 1886-1965). O objetivo que procuramos alcançar ao longo do texto é situar tal objeto na relação entre religião e literatura na modernidade enquanto problema, tal como acima o colocamos. Nestes termos, o Sensacionismo de Pessoa é tomado como ideia central de sua obra poética, bem como chave de compreensão de sua proposta teórica estética modernista.

$\mathrm{Na}$ condição de projeto estético, o Sensacionismo representou a essência do modernismo português em sua primeira geração, tomando a sensação como categoria determinante para a poética, a compreensão e a expressão da condição humana. Desse modo, o Sensacionismo fornecia a Pessoa uma compreensão hermenêutica da arte intrinsecamente vinculada à vida. A problemática da investigação, por sua vez, investe na identificação e na análise do significado existencial-religioso do modernismo de Pessoa, considerando o argumento que acima apontamos com respeito à qualidade redentiva da arte sob a influência do romantismo.

Para tal, em um primeiro momento, delinearemos a relação entre

1 O presente artigo resulta da ampliação e atualização de comunicação de pesquisa cujo texto completo foi publicado nos Anais do $32^{\circ}$ Congresso da Soter, 2019, realizado na PUC-Minas, Belo Horizonte, MG, jul./2019, disponível em http://www.soter.org.br/ anais/32.pdf, data de acesso: 12/Out./2020. 
religião e arte na modernidade como problemática que dirige nossa análise, com base na filosofia da cultura e da religião de Paul Tillich, destacando categorias analíticas e a compreensão hermenêutica que a perspectiva tillichiana propõe para uma abordagem do significado existencial-religioso da arte moderna. Em um segundo momento, definiremos o Sensacionismo como o conjunto dos pressupostos teóricos que nortearam a produção literária de Fernando Pessoa, a partir de seu Manifesto Sensacionista, bem como de um conjunto de poemas heteronímicos. Nesse momento, também lançaremos mão de estudos da obra pessoana para dar relevo ao caráter hermenêutico de sua teoria da criação literária. Por fim, destacaremos, em torno da compreensão hermenêutica da arte, aspectos do potencial analítico da obra pessoana na perspectiva da análise existencial-religiosa da arte de Paul Tillich.

\section{Literatura, crítica e redenção}

A modernidade como crise parece ser um predicado decisivo ao pensamento humanista contemporâneo, em sentido lato. A dúvida como vocação moderna dobrou-se sobre si mesma, como se a sombra passasse a exercer a suspeita acerca do que ela mesma é projeção. Contudo, a crítica da modernidade não deixa de ser uma disputa de natureza linguística e narrativa, no que não há novidade alguma. Trata-se de um procedimento ancestral, recorrente em sítios arqueológicos, em pichações de centros urbanos e no improviso da embolada, sobrepor-se com baixo relevo, tinta ou rimas ao dizer e saber do outro, redefinindo domínios do real sob o efeito de signos e significantes. Mas a singularidade moderna, que teve a pretensão da última palavra e vive a crise e a nostalgia de perdê-la, é justamente a banalização da linguagem resultante da profusão ostensiva de signos e seu correlato, o esvaziamento do poder de significação. Tão verborrágica, a modernidade mostrou-se falaciosa - ou como se diz, "sem palavra".

É por isso que as goivas, tintas e entoadas da crítica moderna parecem tanto se confundir com os muros e paredes que pretende superar sem transcendê-los. Como sintetiza Harold Bloom (2006, p.142), "não parece proveitoso reduzir Javé a uma escolha entre verdade e ficção. Se Javé for ficção, trata-se da ficção mais perturbadora que o Ocidente vislumbrou". O problema da verdade se desloca então para o difuso e decisivo terreno do estranhamento, da alteridade e da subjetividade, cujo domínio escorrega entre os dedos da mão invisivel da razão. Nesses termos, não se trata mais de recobrir a realidade com este ou aquele traço, discurso, conceito; antes, a própria 
linguagem que precisa ser desvelada a partir de uma necessária pós-crítica.

Esta, por sua vez, ganhou corpo desde a segunda metade do século passado, em sucessivas e decisivas investidas no âmbito da filosofia e da arte, com suas repercussões, algumas mais, outras menos tímidas, nas Ciências Humanas como um todo. Da "teoria crítica" de Adorno e Horkheimer e da filosofia política de Hanna Arendt, bem como da "ontologia fática" de Heidegger à "virada hermenêutica" gadameriana e ao "ritornelo" de Deleuze e Guattari e à ética psicanalítica de Lacan, até a "desconstrução" derridiana e o "pós-humanismo" de Foucault fazendo caminhos junto a Estudos Culturais, Teorias Feministas e Queer, bem como acenos à crítica pós/decolonial, temos uma genealogia determinante, que se vale do retorno crítico a clássicos - decisivas releituras de Marx, Kierkegaard, Nietzsche, Freud, Peirce, entre outros, precisam ser lembradas -, para, ao mesmo tempo, deles se desvencilhar, a fim de colocar a problematização do contemporâneo em novas e adequadas bases.

Nesses termos, a linguagem reassume a densidade ontológica que o mito sempre intuiu. Mas, em nosso caso, é no plano discursivo, hermenêutico, político $^{2}$ e epistemológico da linguagem que notamos sua funcionalidade técnica mediadora render-se ao que lhe é imediato: os mundos, as alteridades e as subjetividades que ela carrega consigo. Ou seja, mais que endossar uma relativização pragmática do discurso, que toma a linguagem e a situação comunicativa para um "uso" em função de uma intenção racionalizada, nossas premissas partem do aspecto incondicional e ontológico das narrativas por elas mesmas, na medida em que dão corpo e territorializam mundos vividos - tal como no mito judaico, é no palavrear que céus e terras acontecem.

$\mathrm{O}$ apelo mítico do argumento, por sua vez, nos ajuda a perceber como sintomático o fato de que, de modo geral, autores e autoras do cânone dedicado à análise e denúncia das contradições da modernidade articulam sua crítica não por mera questão de verdade objetiva, mas por uma verdade que faça jus e sentido à realidade. Razão pela qual, as correlações entre tais críticas com a arte - para nosso interesse aqui, especialmente a literatura e o cinema - seja algo tão recorrente. O lugar comum dessas correlações entre

\footnotetext{
2 Em repercussões mais recentes, a dimensão política ganha relevo especialmente a partir da crítica decolonial - mas não porque o político estivesse ausente até então e sim por conta da qualidade política que a hermenêutica decolonial reivindica, ao situar-se no que define como fronteiras subalternizadas pela modernidade (cf. BALLESTRIN, 2013; BAPTISTA, 2016).
} 
mito, pensamento e arte, por sua vez, não é formal ou temático, mas sim dinâmico: o esforço por exercer uma crítica criativa, transformadora, senão redentiva, da realidade - tal como Todorov (2011) o analisa em $A$ beleza salvará o mundo.

A relação entre religião e literatura ganha relevo frente a essa questão que, por sua vez, está no centro da análise religiosa da cultura de Paul Tillich. Sua obra define-se na correlação dialógica com a modernidade e, ao mesmo tempo, numa profunda crítica desta. Isto se evidencia em sua insistência em salvaguardar a noção de "religião" no âmbito da filosofia e da teologia, defendendo sua pertinência ontológica (uma metafísica existencial, se assim pudermos dizer) em base histórico-antropológica. Ao que resultou disso, ele denominou teologia da cultura.

A premissa básica desta é a linguagem como atividade autocriativa e autotranscendente do espírito por meio da qual a realização de sentido efetiva a autoconsciência humana - falaríamos, em linguagem corrente, em processo de subjetivação - no encontro entre si mesmo e realidade, do que resulta a variedade de "universos de sentido" (TILLICH, 1973, p. 56-57; 2005, p. 517-528). Aqui, cultura e religião definem-se como duas funções do espírito e dimensões da linguagem: cultura, sua dimensão formal (sentido condicionado) e, religião, sua dimensão substancial ou qualitativa (sentido incondicionado) (TILLICH, 1973, p. 59-60). Ambas, para Tillich, são "orientações da consciência" no ato de realização de sentido. Isto é, são atitudes subjetivas no acontecimento da linguagem: cultura é a atitude orientada à forma e, religião, a atitude orientada à qualidade da rede de sentidos envolvidos, que ele caracteriza como "incondicional" e que incide sobre a existência humana como referência normativa de conhecimento e ação.

Quando na esfera cultural religiosa, práticas e criações são condicionadas à forma da religião, sendo-lhes atribuídas o valor simbólico de "sagradas"; mas, insistirá Tillich, isso não implica necessariamente em incondicionalidade de sentido. A incondicionalidade de sentido, nesses termos, é paradoxalmente a base infinita para toda criatividade espiritual humana (fundamento), bem como o limite que recai sobre quaisquer condicionamentos culturais (abismo), que a rigor nunca esgotam possibilidades de sentido. Por isso, a noção de incondicionalidade de sentido é critério para a teologia realizar uma "compreensão existencial da religião" concreta, bem como de situações culturais (TILLICH, 2009, p. 81).

O "giro hermenêutico" dessa compreensão de teologia é radicalmente 
O sensacionismo de Fernando Pessoa em diálogo 141 com a análise religiosa da arte de Paul Tillich

antropológico - com Tillich, talvez pudéssemos parafrasear o dito popular "descreva-me o teu Deus e te direi quem tu és". Ao direcionar, por sua vez, sua hermenêutica teológica da cultura para a esfera da arte, as categorias são precisas: a "forma" é dada ao artista, o "tema" é escolhido pelo mesmo e o "estilo" combinará o elemento objetivo da forma e do tema com a subjetividade criadora, dando lugar para questões de ordem última e existencial do artista (preocupação última) orientarem seu trabalho criativo (TILLICH, 1990c, p. 334-335; 2005, p. 29-32). Sempre que uma obra, por meio de seu estilo, expressa incondicionalidade de sentido, há então uma qualidade (não necessariamente conteúdo) religiosa implicada: esta é o objeto da hermenêutica teológica, pressupondo que obras de arte são "documento[s] da existência religiosa" de seu tempo e lugar (TILLICH, 1990, p. 335).

Nestas bases, em suas análises do significado teológico da arte contemporânea, Tillich dá relevo ao expressionismo e ao neorrealismo, destacando no apelo modernista de ambos um argumento teológico profundamente devedor ao romantismo, relacionado à "nostalgia do sagrado" (EAGLETON, 2016) que, para Tillich, se expressa como "vazio sagrado" (TILLICH, 1990a-b; SANTOS, 2018), sugerindo-nos uma significativa correlação entre um esvaziamento teológico da arte e a crise da modernidade na cultura contemporânea.

A partir dessa problemática e quadro conceitual, nossa proposta é identificar elementos que conduzam a uma análise do modernismo português, em Fernando Pessoa, em diálogo com Paul Tillich, a fim de reconhecer o potencial heurístico dessa aproximação relativa à literatura em Língua Portuguesa, bem como delinear possibilidades críticas e criativas para a recepção da obra pessoana em estudos de religião e literatura e do aporte teórico tillichiano, neste mesmo campo de investigação.

\section{Sensacionismo, literatura e religião}

As referências ao Sensacionismo surgem por volta de 1915, com a publicação da revista Orpheu, inaugurando aquilo que iria resultar no modernismo português. A geração de poetas que funda a revista, sob a liderança de Fernando Pessoa e Mário de Sá-Carneiro, traz consigo um desejo de renovação para a literatura portuguesa. Três anos antes, Pessoa fizera a sua estreia proclamando "A Nova Poesia Portuguesa" (MARTINS, 2010, p. 28) na revista Águia e, não satisfeito com os resultados daquela publicação, elaborou com Sá-Carneiro um projeto próprio. Inspirados pelas 
vanguardas europeias e com um apreço particular pela poesia e pela pintura, os intelectuais anunciavam novos tempos, pensavam em integrar culturalmente Portugal com o resto do continente. O modernismo português trouxe em seu bojo um sentimento de que "é preciso ter um pouco de Europa na alma" (MARTINS, 2010, p. 564-566), no sentido de que a nova poesia precisava ser menos saudosista, olhar menos para o mar, símbolo das glórias do passado, e voltar os olhos para o continente. Esse movimento buscava acertar o passo com a Europa, tornar Portugal mais integrado com o cenário intelectual, com o desenvolvimento cultural dos grandes centros europeus. No entanto, num primeiro momento, os esforços daquela geração provocaram apenas o escárnio e o embaraço de uma classe intelectual profundamente avessa ao ímpeto moderno ali anunciado.

Enquanto a empreitada da revista esbarrava na recepção controversa de um público ainda apegado à estética calejada das escolas passadas, o Sensacionismo se comportou como um rótulo digno de amparar a liberdade criativa pessoana. Era um protótipo de corrente literária que se dedicava a propor a ideia de síntese de todas as outras, libertando o poeta da cartilha específica de uma escola particular. "Apesar do seu teor paradoxal, o Sensacionismo consegue o prodígio de não perder o sentido, porque se mantém focado no conceito de sensação" (PESSOA, 2015, posição 10), é o que nos diz o estudioso Fernando Martins na introdução do livro que organizou, reunindo os diversos escritos do poeta a respeito do Sensacionismo, da Orpheu e das suas relações com o modernismo. Na medida em que o ideal de sensação sedimentava uma visão particular sobre a vida, ele concedia aos versos de Pessoa e especialmente ao heterônimo Álvaro de Campos (listado como um dos participantes e fundadores da revista) aquela característica que findou por marcar na história a poesia pessoana como uma produção capaz de impressionar, emocionar, ou como ele diria, capaz de suscitar sensações em quem lê. Um ponto pacífico para muitos estudantes da obra do poeta é que o Sensacionismo "ajuda a esclarecer o nascimento dos heterônimos” (SILVA FILHO, 2016, p. 140), pois a heteronímia ${ }^{3}$ consiste na realização máxima do ideal de síntese defendido por Pessoa nos seus escritos

\footnotetext{
3 Termo que se refere aos heterônimos. Enquanto o pseudônimo é apenas um nome diferente com que um autor assina a sua obra, o heterônimo é uma criação ficcional completa, a criação de uma individualidade fictícia com origem, crenças, personalidade e até mesmo dados biográficos bem estabelecidos. O seu estilo de escrita também costuma apresentar diferenças consideráveis em relação ao artista criador. (MARTINS, 2010, p. 333)
} 
acerca do Sensacionismo.

Com a possibilidade de ter nos seus poemas uma construção fictícia, uma ficção de poesia e não uma expressão de sentimentos pessoais, o poeta ficava livre para se expressar dentro de um espectro de maior variedade estética e, dessa forma, os seus três principais heterônimos dialogavam entre si ao representar diversas perspectivas no acabamento formal dos versos. Cada um deles foi construído com toda a complexidade que um dramaturgo utiliza para compor personagens, sem poupar dados biográficos, detalhes de nascimento e personalidade. Ricardo Reis explorava a tendência clássica, com um certo frescor árcade nas evocações da cultura grega e na inspiração clássica das suas odes; Alberto Caeiro trazia o frescor da simplicidade, representando a perspectiva de um homem simples do campo, vendo a natureza sem os filtros de qualquer erudição; por sua vez, Álvaro de Campos expressava todo o desassossego intelectual do homem do seu tempo. Campos era aquele que representava uma escrita propositiva, aquele que materializava um projeto de escrita completamente original diante dos demais no que se refere à forma.

Representar esse encontro de perspectivas, ser e sentir na poesia toda essa multiplicidade era o ideal sensacionista, era o diferencial que garantia uma identidade definitivamente modernista para a obra. O que se deve ressaltar é que a poesia de Pessoa era moderna não apenas no lirismo desbocado de Campos, posto que mesmo no formalismo de Reis ou no olhar brejeiro de Caeiro existia essa proposta ficcional, sintética, no que diz respeito à tradição literária. Trata-se de uma síntese, de uma referência a outros estilos, sem com isso se igualar a cada uma das correntes que referencia. A imparcialidade desse eu-lírico ficcional adicionou à poesia de Pessoa um traço distintivo, reforçando a natureza modernista da sua proposta. "O poeta está pois condenado ao fingimento. E a consciência do fingimento se manifesta com a má consciência do mentiroso" (PERRONE-MOISÉS, 2001, p. 25). Eis o poeta sensacionista, o poeta fingidor. Eis um dos principais elementos a destacar em Pessoa, na sua postura de poeta modernista, menos preocupada com a descoberta de uma verdade estética definitiva, solidificada no manifesto de uma escola literária, e muito mais preocupada com as questões do ser e do mundo, digase de passagem, um mundo pós-morte de Deus, como antecipara Nietzsche, sob a nostalgia do absoluto e, ao mesmo tempo, fervorosamente disposto ao método científico, ainda que desejoso por transcendê-lo por meio da, ou antes, na própria sensação estética - como vimos acima. Um ponto de vista 
assim configurado, movido por uma "coragem de desesperar-se" por meio do gesto poético (TILLICH, 1992, p. 111-112), parece refletido nos versos de Campos, escrito ao rufo dos desdobramentos que dariam na Primeira Grande Guerra (PESSOA, 2010, p. 91):

Quando eu morrer, Quando me for, ignobilmente, como toda a gente, Por aquele caminho cuja ideia se não pode encarar de frente, Por aquela porta a que, se pudéssemos assomar, não assomaríamos, Para aquele porto que o capitão do Navio não conhece, Seja por esta hora condigna dos tédios que tive, (...)

Seja por esta hora que me leveis a enterrar, Por esta hora que eu não sei como viver, Em que não sei que sensações ter ou fingir que tenho,

(...)

Cruza as mãos sobre o joelho, ó companheira que eu não tenho nem quero ter,

Cruza as mãos sobre o joelho e olha-me em silêncio

A essa hora em que eu não posso ver que tu me olhas,

Olha-me em silêncio e em segredo e pergunta a ti própria

- Tu que me conheces - quem eu sou... ${ }^{4}$

O protesto modernista por sentido da realidade, bem como a vocação fúnebre da arte (TARKOVKSI, 2002, p. 49), está bem expressa nessas linhas. Reflete também o período complicado da nossa história, período de

4 Poema assinado pelo heterônimo Álvaro de Campos em 30/06/1914 (PESSOA, 2010, p. 91). A respeito das datas, é interessante mencionar que Fernando Pessoa é profundamente marcado pelo seu caráter ficcional ao escrever. Numa carta de 1931 a Gaspar Simões, ele afirma que o ponto central da sua personalidade artística é ser um "poeta dramático", dotado da "exaltação íntima do poeta" e da "despersonalização do dramaturgo" (PESSOA, 2020, posição 1511). Por conta disso surgem questionamentos sobre a possibilidade de ter estabelecido datas fictícias tanto para escritos quanto para os seus autores também ficcionais. No entanto, algumas datas são aceitas por diversos especialistas em sua obra, entre elas tem grande importância a produção poética de Pessoa em 1914, o ano em que alguns dos principais heterônimos são estruturados, como Alberto Caeiro na data de 08/03/1914 (MARTINS, 2010, p. 326), momento do famoso êxtase em que teria composto diversos poemas de uma vez só, e também alguns escritos de Álvaro de Campos, como é o caso do poema citado. Mesmo que considerássemos a data do poema como uma atribuição fictícia, ainda teríamos nela um importante significado, pois estaríamos diante da escolha proposital do poeta em relacionar o conteúdo dos versos a um determinado momento histórico. 
grandes guerras e de profundas transformações culturais, no qual Pessoa desenvolve sua obra. Tillich se refere ao começo do século XX como uma época de "transformação técnica do mundo" (TILLICH, 2009, p. 84). Época em que teríamos perdido a "dimensão da profundidade no encontro com a realidade" (TILLICH, 2009, p. 84), cujo efeito mais significativo, do ponto de vista religioso, foi o de uma "revolta existencial" no âmbito da filosofia e da arte (TILLICH, 1992, p. 108ss). Nesta última, a ideia de "vazio sagrado" expressa, para Tillich, a reivindicação do expressionismo e do neorrealismo, entre outras vanguardas em que o significado religioso se dá como expressão de "coragem do desespero".

A questão final do poema supracitado se forma a partir da certeza do eu-lírico em relação a sua condição de finitude: é a partir do confronto com o não-ser como constitutivo da existência, expresso no encontro de si com sua própria morte, que se estabelece a interrogação sobre o si mesmo. Tillich nos ajuda a compreender este aspecto como algo próprio ao ser humano, único a formular e expressar, na metalinguagem da arte, a pergunta ontológica, "porque só ele é capaz de olhar para além dos limites de seu próprio ser e de todo outro ser” (TILLICH, 2019, p. 195). A própria condição de ser pressupõe a finitude, principalmente na circunstância em que a experimentação do finito se dá a partir do olhar para si mesmo numa atitude de reconhecimento da própria “infinitude potencial” (TILLICH, 2019, p. 199).

Ao reconhecer, no princípio modernista do Sensacionismo, o sintoma das reflexões decisivas do ser humano acerca de si mesmo no início do século XX, começamos a vislumbrar o caminho da questão. Pessoa afirmava que "O Sensacionismo visa a não compreender o universo. A realidade é a incompreensibilidade das coisas" (PESSOA, 2015, posição 56), ressaltando a sua proposta de não erigir uma leitura pronta ou uma narrativa explicativa da realidade. A sua perspectiva contemplava um papel interpretativo para a arte, tal como se pode ler em suas palavras: "A arte é uma interpretação da Vida" (PESSOA, 2015, posição 19), pensamento que o conduzia ao papel da "sensação como realidade essencial" (PESSOA, 2015, posição 56). Ora, se este lirismo se baseia na ideia da sensação como única coisa que nos resta, visto que, sob esta perspectiva, todo vestígio de realidade parece proceder dos nossos estímulos sensoriais a respeito do mundo, é natural ter sobre tais estímulos uma certa primazia na elaboração da escrita. A proposta seria "sensacionar a inteligência" (PESSOA, 2015, posição 42). Pessoa pretende com isso colocar a sensação como mediação estética da obra, assumindo esse 
papel mediador direcionando o estímulo proveniente da inteligência.

Toda a tendência da arte tem sido intelectualizar a sensação ou o sentimento. Propomo-nos inverter este processo, e sensacionar a inteligência. Em vez de partirmos da sensação, partimos da ideia; em vez de empregarmos a inteligência como mediador plástico, empregamos a sensação (PESSOA, 2015, posição 42).

Com isso Pessoa pretende uma inversão em relação ao que acredita ser a tendência corrente na poesia. Se antes o poeta romântico e simbolista partia da sensação, tentando encaixar sua emoção numa forma racionalizada através da construção do seu verso na escrita, intelectualizando esse processo emocional no papel através das palavras, sentenças, metáforas e demais recursos técnicos, ele então propõe algo diverso. $\mathrm{Na}$ medida em que parte do que classifica como ideia, parte então de uma abordagem que privilegia essa elaboração mental e a traz para o verso por intermédio da categoria de sensação, ou seja, partindo de uma organização de pensamento centrada na ideia, na inteligência. Por isso a própria elaboração do seu verso assume um aspecto mais prosaico, mais organizado sob a tutela da mente, para que somente embasada nessa condição, a elaboração mental se deixe mediar pela sensação, na medida em que tal sensação delimita os meios, o caminho pelo qual busca descrever, trazer para o seu desenrolar as motivações emocionais. Este recurso proporciona aquela característica que por vezes parece reproduzir no poema o caminho de um fluxo de consciência do eu-lírico, como se ouvíssemos a sua voz interrogando o mundo, argumentando acerca do que sente. Poderíamos resumir a poesia sensacionista como aquela que acontece no caminho da mente ao coração e não do coração para a mente.

Esse ímpeto questionador diante de uma tradição estabelecida é um fator decisivo para a aproximação dos membros do movimento gerador da revista Orpheu, todavia é importante mencionar o fato de que a geração órfica teve dois legados. O primeiro teve na revista o símbolo de uma ruptura estética empreendida pelos artistas durante o pequeno tempo de atividade da publicação, o segundo se estabelece em decorrência do primeiro, como uma consequência da revista. Trata-se principalmente da repercussão da produção artística de Fernando Pessoa, Mário de Sá-Carneiro e Almada Negreiros nas décadas seguintes. Seria este o "movimento que constitui a explosão portuguesa da Vanguarda” (MARTINS, 2017, p. 89). É neste segundo legado que se pode enxergar a consolidação do modernismo português.

Especificamente na obra literária pessoana, a influência vanguardista 
é sentida mais claramente no futurismo impresso pelos versos de Álvaro de Campos em poemas como Ode Triunfal e Ode Marítima. A natureza mordaz do versejar de Campos traz consigo a ironia, o despojamento, a ruptura com a tradição, ao mesmo tempo em que propaga o encantamento com a presença dos novos elementos da tecnologia. É a manifestação da empolgação futurista que antecede a Primeira Guerra, dotada de uma profunda expectativa de progresso, até mesmo de um certo louvor bélico. $\mathrm{Na}$ literatura tivemos a inserção desses elementos como partes do cotidiano, lado a lado com as menções que claramente anunciavam novos tempos, um novo século e um homem já bastante diferente daquele do final do século anterior. O poema a seguir (PESSOA, 2010, p. 80-84) é datado de junho de 1914, exatamente um mês antes do estopim da Primeira Guerra:

A maravilhosa beleza das corrupções políticas, Deliciosos escândalos financeiros e diplomáticos, Agressões políticas nas ruas, E de vez em quando o cometa dum regicídio Que ilumina de Prodígio e Fanfarra os céus Usuais e lúcidos da Civilização quotidiana!

Notícias desmentidas dos jornais, Artigos políticos insinceramente sinceros, (...)

Amo-vos a todos, a tudo, como uma fera. Amo-vos carnivoramente.

Pervertidamente e enroscando a minha vista Em vós, ó coisas grandes, banais, úteis, inúteis, Ó coisas todas modernas, Ó minhas contemporâneas, forma atual e próxima Do sistema imediato do Universo! Nova Revelação metálica e dinâmica de Deus!

Ó fábricas, ó laboratórios, ó music-halls, ó Luna-Parks, Ó couraçados, ó pontes, ó docas flutuantes $\mathrm{Na}$ minha mente turbulenta e encandescida

Possuo-vos como a uma mulher bela, Completamente vos possuo como a uma mulher bela que não se ama, Que se encontra casualmente e se acha interessantíssima.

(...)

Eu podia morrer triturado por um motor Com o sentimento de deliciosa entrega duma mulher possuída. 
Atirem-me para dentro das fornalhas!

Metam-me debaixo dos comboios!

Espanquem-me a bordo de navios!

Masoquismo através de maquinismos!

Sadismo de não sei quê moderno e eu e barulho!

(...)

Como eu vos amo a todos, porque sois assim,

Nem imorais de tão baixos que sois, nem bons nem maus,

Inatingíveis por todos os progressos,

Fauna maravilhosa do fundo do mar da vida!

Se pensarmos a arte como condensação do encontro entre o ser humano e o mundo, tendo em mente a percepção tillichiana de que "o ser humano experimenta a si mesmo como possuindo um mundo ao qual pertence" (TILLICH, 2019, p. 179), se estivermos também considerando a premissa de que a arte, como produto desse encontro do ser humano com o mundo, "traz consigo uma autocompreensão humana" (SANTOS, 2017, p. 356), capaz de ter na expressão de subjetividade do artista o apelo incondicional de poder de ser e sentido de uma preocupação última, então certamente perceberemos na poesia sensacionista de Pessoa "o potencial criativo e transcendente em relação a situação cultural” (SANTOS, 2017, p. 356) da qual ela faz parte. Diante da aproximação entre cultura e religião, Tillich entende a cultura como a expressão da totalidade da autocompreensão criativa do homem. Para ele, é justamente na arte que essa atividade de autocompreensão se apresenta mais visivelmente (MANNING, 2009) 5 .

Tillich concebe a obra de arte a partir da tríade de elementos estruturais da linguagem, presentes na sua constituição enquanto manifestação de criatividade cultural: Form (forma), Inhalt (tema) e Gehalt (substância) (TILLICH, 1987, p. 133ss; MANNING, 2009, p. 157). Sob a noção de forma, podemos compreender aquele elemento definitivo no sentido de determinar a natureza da obra em questão. "A forma torna uma criação cultural aquilo que ela é" (TILLICH, 2019, p. 520), definindo sua organização e unidade, pois deriva da livre escolha do artista ao selecionar os mecanismos e aparatos técnicos que fornecem suporte à obra no processo de criação artística

\footnotetext{
5 "In other words, art is the clearest indicator of the self-interpretation of a particular situation; if culture as a whole is the expression of the totality of humanity's creative self-interpretation, it is in art that the character of this self-interpretative activity becomes most clearly visible" (MANNING, 2009, p. 156).
} 
(MANNING, 2009). O segundo elemento é aquele que, embora objetivo porque relativo à realidade, se dá a partir da escolha subjetiva do artista, a natureza temática expressa na obra. Sobre este conteúdo temático, vale ressaltar o seu lugar secundário na perspectiva de análise tillichiana, que visa identificar e interpretar o caráter religioso de uma obra de arte. Porque este, segundo Tillich, se dá por meio do estilo, que não se define pelas escolhas temáticas e sim na dinâmica criativa que sintetiza forma e tema numa obra de arte (MANNING, 2009; SANTOS, 2017). É a razão pela qual ele afirma ser possível identificar numa obra de Cézanne ou de van Gogh elementos substancialmente mais religiosos do que numa pintura sacra de Jesus. "É no elemento Gehalt que predomina a identificação do estilo religioso de uma obra de arte" (MANNING, 2009, p. 158 - nossa tradução) ${ }^{6}$.

A substância de uma obra escapa ao controle do artista. "Enquanto o tema é escolhido e a forma é buscada, a substância é, por assim dizer, o solo no qual ela cresce" (TILLICH, 2019, p. 520). Daí a necessidade de metáforas: Tillich chama essa dimensão da subjetividade, que é a partir da qual ele define religião como "orientação à incondicionalidade de sentido", como preocupação última. Por isso, a substância de uma obra de arte é o elemento formado inconscientemente, responsável por conceder à "pessoa que cria a paixão e o impulso, e às suas criações o significado e o poder de sentido" (TILLICH, 2019, p. 520). Ora, considerando que é, portanto, na dimensão do estilo, no elemento substancial de uma obra de arte o fator para o qual se deve atentar em busca de sua qualidade teopoética, sem perder de vista que "a poesia é a expressão mais direta da substância através de um indivíduo" (TILLICH, 2019, p. 520), temos as categorias básicas para uma análise do significado religioso da obra de Fernando Pessoa.

\section{Conclusão}

Nosso esforço, neste artigo, foi o de traçar uma relação entre religião e literatura como problematização da modernidade, retomando a centralidade da noção de linguagem para se pensar uma ontologia sensível à condição humana. Como premissa, a própria noção de religião e cultura que tomamos da hermenêutica teológica de Tillich nos coloca tanto na condição da linguagem quanto na da hermenêutica. A sugestão inicial de um retorno ao mito, não mais por sua estrutura do que por sua significação e qualidade

6 Trecho original: "And it is the element of Gebalt that predominates in the identification of an artworks's 'religious style"'. 
existencial, nos encaminham a uma compreensão na qual arte e religião estão mais relacionadas que distintas, em função daquilo que as une, a dinâmica realizadora de sentido de vida e de mundo.

Nesse cenário, em relação à literatura, destacamos que sua qualidade crítica se correlaciona a uma expectativa romântica redentiva, que assume o luto resultante do anúncio nietzschiano numa atitude apofática, desde a qual opera criativamente o que Tillich chama de "vazio sagrado" na arte moderna - reivindicando, nestas bases, que esta "não é propaganda e sim revelação" (1992, p. 115). De tudo o que esta revelação poderia sugerir, para nossa análise, o que privilegiamos é a percepção da crise da modernidade.

A partir das premissas e das categorias que a teologia da arte de Tillich nos oferece, ensejamos a relação entre o Sensacionismo de Fernando Pessoa e a perspectiva de análise da arte moderna que Tillich nos media por meio de sua teologia da arte. As características modernistas da poética e da teoria estética de Pessoa às quais destacamos, por sua vez, nos sugerem uma qualidade existencial-religiosa - em termos tillichianos - na obra de Pessoa, que merecem atenção sob dois aspectos especialmente: primeiro, a eleição da noção de sensação como dimensão primeira e fundamental do encontro do poeta com o mundo condensada na obra de arte, do que implica uma radical orientação à imanência e à finitude como condição para a autotranscendência estética - se é que esta ocorre de fato e, se sim, em que termos. Disso decorre, em segundo lugar, o que deixamos no nível da sugestão, uma análise desse sujeito lírico, exponenciado por seus heterônimos, como expressão dos próprios limites da aposta na subjetividade criativa que, como um ato de coragem de ser como si próprio, está na base do protesto e da atitude existencial que, na perspectiva tillichiana, anima a arte moderna nos termos de uma "coragem de desesperar-se".

\section{Referências}

BALLESTRIN, Luciana. América Latina e o giro decolonial. Revista Brasileira de Ciência Política, n. 11, p. 89-117, Mai./Ago. 2013.

BAPTISTA, Paulo A. N. Pensamento decolonial, teologias pós-coloniais e Teologia da Libertação. Perspectiva Teológica, v. 48, n. 3, p. 491-517, Set./Dez. 2016

BLOOM, Harold. Jesus e Javé: os nomes divinos. Trad. José Roberto O’Shea. Rio de Janeiro: Objetiva, 2006.

EAGLETON, Terry. A morte de Deus na cultura. Trad. Clóvis Marques. Rio de janeiro: Record, 2016. 
MANNING, Russel Re. Tillich's theology of art. In.: MANNING, Russel Re (Ed.). The Cambridge companion to Paul Tillich. Cambridge, UK: Cambridge University Press, 2009, p. 152-172.

MARTINS, Fernando Cabral. Dicionário de Fernando Pessoa e do Modernismo Português. São Paulo: Leya, 2010.

Introdução ao Estudo de Fernando Pessoa. Cotia, SP: Ateliê Editorial, 2017.

MATOS, Anderson H. Origem do Sensacionismo no grupo Orpheu. Nau literária: crítica e teoria de literaturas, ano 11, vol. 11-2, Porto Alegre, jan/jun 2015.

MOISÉS, Massaud. Fernando Pessoa: O Espelho e a Esfinge. São Paulo: Cultrix, 2009.

PERRONE-MOISÉS, Leyla. Fernando Pessoa: Aquém do eu, além do outro. $3^{\mathrm{a}}$ ed. rev. e ampl. São Paulo: Martins Fontes, 2001.

PESSOA, Fernando. Mensagem. São Paulo: Martin Claret, 2006a.

Obra Completa de Fernando Pessoa V: Escritos sobre Arte e Literatura (Edição Definitiva). Edição Kindle, 2020.

Obra Completa de Fernando Pessoa VII: Escritos sobre Filosofia (Edição Definitiva). Edição Kindle, 2020a.

Obra Poética Completa: Volume Único (Edição Definitiva). Edição Kindle, 2020b.

Poemas Completos de Alberto Caeiro. São Paulo: Martin Claret, 2007.

Poesia Completa de Álvaro de Campos. Edição Teresa Rita Lopes, $1^{a}$ reimpressão. São Paulo: Companhia das Letras, 2010.

Poesia de Ricardo Reis. São Paulo: Martin Claret, 2006b.

Sobre o Orpheu e o Sensacionismo. Organizador: Fernando Cabral Martins. Lisboa: Assírio \& Alvim, 2015. (versão e-book adquirida no site www.wook.pt)

SANTOS, Joe Marçal G. Cinema, realismo e revelação: um diálogo com Paul Tillich e André Bazin. Revista Eletrônica Correlatio v. 16, n. 1. São Paulo: UMESP, junho de 2017.

Literatura e religião: a relação buscando um método. Horizonte. Belo Horizonte, v. 10, n. 25, p.29-52, jan./mar. 2012.

SILVA FILHO, Gilvan J. "Eu não tenho filosofia: tenho sentidos...”: fenomenologia e Sensacionismo em Alberto Caeiro. Filosofia e Poesia: congresso internacional de língua portuguesa. Porto: Universidade do Porto, Faculdade de Letras, 2016.

TARKOVSKI, Andrei A. Esculpir o tempo. $2^{a}$ ed. Trad. Jefferson Luís Camargo. São Paulo: Martins Fontes, 2002.

TILLICH, Paul. A Coragem de Ser: baseado nas Conferências Terry, pronunciadas na Yale University. Trad. Eglê Malheiros. $3^{a}$ ed. Rio de Janeiro: Paz e Terra, 1992.

Existencialist aspect of modern art (1956). In.: PALMER, M. (ed.). Paul Tillich Main works/Hauptwerke: writings in the philosophy of culture. Berlim/New York : De Gruyter - Evangelisches Verlagswerk BmbH, 1990a. v.2, p. 269-279. 
152 Joe Marçal Gonçalves dos Santos

Ivanilton Aragão de Moura

Teologia da cultura. Trad. Jaci Maraschin. São Paulo: Fonte Editorial, 2009.

Teologia Sistemática. Trad. G. Bertelli; G. Korndörfer. Revisão: Ênio R. Mueller. 8.ed. rev. São Leopoldo: Sinodal, 2019.

Religion and secular culture (1946). In.: PALMER, M. (ed.). Paul Tillich Main works/Hauptwerke: writings in the philosophy of culture. Berlim/New York : De Gruyter - Evangelisches Verlagswerk BmbH, 1990b. v.2, p.197-207.

Religionphilosophie (1925). In: RATSCHOW, Carl H.; CLAYTON, John. (Eds.) Paul Tillich Main Works / Haupwerke: Writings on the philosophy of religion. Berlin. New York: Evangelisches Verlangswerk. De Gruyter, v. 4, 1987, p. 117-170.

Zur Theologie der bildenden Kunst und der Architektur (1961). In.: PALMER, M. (ed.). Paul Tillich Main works/Hauptwerke: writings in the philosophy of culture. Berlim/ New York : De Gruyter - Evangelisches Verlagswerk BmbH, 1990c. v.2, p. 333-344.

TODOROV, T. A beleza salvará o mundo: Wilde, Rilke e Tsvetaeva: os aventureiros do absoluto. Trad. Caio Meira. Rio de Janeiro: DIFEL, 2011.

Submetido em: 30-9-2020

Aceito em: 29-11-2020 